\title{
TRANSFORMING SOUTH AFRICA'S UNIVERSITIES OF TECHNOLOGY: A ROADMAP THROUGH 4IR LENSES
}

\author{
Muthoni MASINDE ${ }^{1 *}$ and Peter A. ROUX ${ }^{2}$ \\ ${ }^{1 *}$ Department of Information Technology, Central University of Technology, Free State, \\ South Africa \\ ${ }^{2}$ UFS Business School, University of the Free State, South Africa \\ Email: muthonimasinde@gmail.com ${ }^{1 *}$; pieter.roux@icloud.com²
}

\begin{abstract}
Since their birth in the $6^{\text {th }}$ century, universities have undergone different forms of transformations, especially of structural, ideological, and epistemological nature. Recently, the emergence of the fourth industrial revolution (4IR) has triggered a wave of such transformations and just like other industrial revolutions, university management ought to be cautious as such transformations could exacerbate existing inequalities between the rich and the poor students. To this end, a clear roadmap for such a transformation becomes critical. This is the contribution of this paper. We achieve this through a bibliometric analysis of the state of scientific research into the 'university transformation' topic, with a special focus on South Africa's (RSA) context. The content of the identified scientific publications on RSA was further subjected to thematic analysis leading to the revelation that decolonisation, community engagement and structural transformation, are the main research themes. It also emerges that RSA universities have not embraced 4IR as a lens through which to pursue transformation. On the other hand, the RSA government launched the project: "Transformation at Public Universities" during the 2017/18 planning year. Subsequently, all universities in the country adopted and rolled out a customised transformation agenda. Among these universities, are the six universities of technology (UoTs), which, for historical reasons, the transformation project presents unique challenges and opportunities. Created slightly after the millennium, UoTs are still seen as critical role players in the third mission of universities, that of "achieving economic growth and social progress". These findings, as wells as the existence of systemic exclusion, marginalisation, and discrimination (especially along racial lines) in RSA universities, defines our proposed roadmap. Using one of the UoTs and Massive Open Online Courses (MOOCs) as the reference, the proposed university transformation roadmap is supported by empirical data on the assessment of the readiness of students to adopt 4IR technologies.
\end{abstract}

Keywords: Fourth industrial revolution (4IR), universities of technology (UoTs), Massive Open Online Courses (MOOCs), university transformation, university transformation

\section{INTRODUCTION}

Institutional transformation can be described as the transition from one state to another through a process of undergoing changes to the structure, nature and appearance (Preez, Simmonds, and Campus, 2016) of the concerned institution. The transformation process is, therefore, highly complex and is influenced by both internal and external factors. Unique history such as apartheid, coupled with peculiar realities such as institutionalised inequality (SACHR, 2018; Soudien-Report, 2008), makes transformation of South Africa's higher 
education (HE) sector an extremely attractive research topic as well as fodder for many policy debates. This could explain the existence of a generous number of scientific publications and government reports on this topic. Some of these reports are described in (Luvalo, 2019; Preez et al., 2016). Several research publications under this topic are also analysed in the current paper. The key elements of transforming HE institutions converge to structural discourses, ideological shifts, curriculum change and overhauling of both the institutional management and organisational culture. Apart from the two (that is, motivation to expand higher education and to increase participation) globally accepted drivers for HE transformation, other unique phrases associated with South Africa's HE transformation are (1) affirmative action to ensure wider access to black African students; and (2) Africanisation and decolonisation of the curriculum (Luvalo, 2019).

The uniqueness of the HE transformation agenda in South Africa is to be found in the alarming levels of inequality, especially along racial lines. On this, South Africa has consistently held the first position (Barr, 2017) as the most unequal country in the world sometimes interchanging the position with war-torn countries such as the Central Africa Republic. In the most recent (2019) World Bank and United Nations Development index for inequality, South Africa scored the highest Gini index value of $63.38 \%$ and a starkest Palma ratio value of $71.4 \%$ respectively (United Nations Development Programme, 2019). It should therefore not be surprising that the phrase; "a country of three-nations" has been used to describe South Africa (Bond, 2007). South Africa's Higher Education sector has not been spared by these alarming levels of inequality. This is a matter of grave concern as captured in the phrase below(SACHR, 2018): "More than 20 years into the country's democracy, South Africa continues to face deeply entrenched inequalities in all spheres of our society, including our public universities. Despite notable progress made in addressing historical inequalities in public universities, patterns of systemic exclusion, marginalisation and discrimination persist."

In the same report, fifteen reasons for lack of (or slow) transformation are addressed. Top of the list of the reasons is: "the lack of a uniform understanding of what transformation means". For this, the following contextualised (to the public universities) definition is provided in (SACHR, 2018). "... a transformed system of higher education is one that is free from all forms of unfair discrimination (whether direct or indirect) and artificial barriers to access and success, as well as one that is built on the principles of social inclusivity, mutual respect and acceptance.". Three pillars of HE transformation have been identified as (1) policy and compliance, (2) epistemological, and (3) institutional culture. Of focus to this paper is the epistemological pillar which entails interrogation of both the sources of knowledge as well as how it is passed to the student (Luvalo, 2019). For these, it is the thesis of this paper that the technologies associated with 4IR can be used to remove artificial barriers to access and success of university students in South Africa.

The fourth industrial revolution (also known as Industry 4.0 or $4 \mathrm{IR}$ ) has become a reality to reckon with (Sackey, and Bester, 2016) - it had matured faster than it was forecasted just over three years ago when it was said: "To be sure, the Fourth Industrial Revolution is still in its nascent state. But with the pace of change and disruption to business and society so swift these days, the time to join in is now." (World Economic Forum, 2018). There is evidence that 4IR can indeed influence not just the curriculum, but all aspects of HE, including vision, policy, planning and implementation of strategies such as change management and research sharing (ISOCARP, 2018). The world is witnessing re-alignments of all kinds - all aimed at embracing the unstoppable 4IR. Like other socio- economic sectors, South Africa's higher education sector will not be spared by the aftermath of the 4IR (Sackey and Bester, 2016). So dramatic will be the revolution that it will outwash the $19^{\text {th }}$-century revolution in which the research university evolved. This revolution will also be much more complex than the scope and diversity-based revolution of the past half-century(Altbach, Reisberg, and Rumbley, 2009). 
The issue of transforming public universities in South Africa is a national agenda by the government. To this end, all universities in the country have taken up the recommendations in the South African Human Rights Commission report on "Transforming Public Universities" (SACHR, 2018) and instituted university-level transformation agenda. Of importance to the work presented in this paper is the categorisation of South African universities into three: the traditional universities, comprehensive universities and universities of technology(UoTs) (Bunting and Cloete, 2010). The UoTs present unique opportunities and challenges in the face of transformation. For instance, more than $90 \%$ of UoTs students are black, two, the UoTs are just over ten years old, and three, they have limited resources (Mtshali and Sooryamoorthy, 2018). In this paper, we use one of the UoTs as a reference in developing a blueprint on how UoTs' top management can leverage 4IR to ensure implementation and success of the transformation agenda.

The Central University of Technology, Free state (CUT), has not been left behind in the inevitable race for/towards 4IR. CUT adopted the leadership slogan: "Reimagining CUT" at the end of 2016(CUT, 2016). During that year, the implementation punchline for the slogan was coined as "Reimagining CUT: The Year of Innovation and Entrepreneurship", the 2017 one was, "Reimagining CUT: The Year of the Human Project" while the 2018 one was: "Reimagining CUT: Embracing Servant Leadership". This is all in line with CUT's special project dubbed "Reimagining CUT as a transformative University and 'model' UoT in Africa, impacting on the socio-economic development of the Central region of South Africa and beyond". The rationale for the project is anchored within the national initiative under the theme: "Transformation at Public Universities in South Africa" (SACHR, 2018). In the case of CUT, the Transformation Project is a university-wide drive towards new institutionalism (change), consisting of ten focus areas. One of these states: "Reimagining CUT as a transformative University." A look at similar transformation projects from other UoTs reveal a similar pattern; frameworks aimed transforming at all aspects of universities. These are, teaching and learning, research, engagement, governance and leadership, language, institutional culture, student life and administration support.

This paper provides details on how CUT can leverage 4IR to accelerate the transformation agenda; this is done through the sub-them: "Reimagining CUT through 4IR lens". It is worth noting that CUT has already made some strides towards embracing 4IR. The first one is CUT's stakeholders' sensitisation on 4IR as well as the creation of a research centre focusing on 4IR - the Centre for Sustainable Smart Cities 4.0. This points to awareness and commitment by CUT towards leveraging the 4IR in its current and future agenda. It is on this basis that the research objective of developing a roadmap for the adoption of 4IR in CUT's transformation agenda is proposed. In this context, CUT is used as the case study that represents other South African universities of technology (UoTs). This objective is pursued through the following research questions:

a) What are the main themes that define the current research into higher education institutions' transformation in South Africa, and to what extent are they incorporating the 4IR theme?

b) To what extent are students at the South African universities of technology ready for 4IR-driven curriculum transformation? 


\section{LITERATURE REVIEW}

\subsection{The 4th industrial revolution (4IR) - the basics}

The term Industry 4.0 was first published in Germany in 2011 - it was associated with an economic development proposal based on high-tech strategy (Mosconi, 2015). Subsequently, this launched the fourth industrial revolution (Roblek, Meško, and Krapež, 2016). In Sackey and Bester (2016) various aspects of the definition of 4IR are presented, one of these definitions reads as follows: "a collective term for technologies and concepts of value chain organisation which draws together Cyber-Physical Systems, the Internet of Things, and the Internet of Services."

The duo (Suckey and Bester, 2016) also diagrammatically presented eight value drivers and 24 dependent industry levers in 4IR. Some of the distinct functional features of 4IR include modularised flexibility, interoperability, and virtualisation. The first industrial revolution was based on steam and water power; it emerged from Newton's law of motion which enabled comprehension and quantification of motion (Xing and Marwala, 2018). The 'revolution' here was in the mechanisation of many manual events that were carried out by humans. The second industrial revolution was ushered by the unification of magnetic and electric forces (hence generation of electricity and the emergence of the electric motor); this was the work of Faraday and Maxwell. This led to revolutionised operations on the assembly lines. Finally, the discovery of a transistor ushered in the third industrial revolution which formed the precursor for the centre stage of the widely known electronic/digital age driven by computers and the internet (Kelly, 1998). The first three industrial revolutions were thus characterised by advances in technology. To a large extent, all the first three industrial revolutions enabled the mechanical work done by human beings to be done by machines, thus freeing humans to do the work that required cognitive capability that machines lacked (Bloem et al., 2014).

On the other hand, the fourth industrial revolution, or industry 4.0 or $4 \mathrm{IR}$, is different from the first three in two major ways: firstly, it represents the combination of cyber-physical systems, the Internet of Things, and the Internet of Systems. This gives rise to the idea of, for instance, smart factories in which machines are augmented with web connectivity and connected to a system that can visualise the entire production chain and make decisions on its own. Secondly, the technologies that underpin 4IR are no longer restricted to mechanical work, as they are capable of cognitive processing just like humans. Xing and Marwala (2018) present three hallmarks of 4IR as (1) Digitisation and integration of vertical and horizontal process across the entire organisation's operations also referred to as the shift from centralised to the decentralisation of production; (2) Digitisation of products and services that entails the application of artificial intelligence to ensure self-regulated production (e.g. only on demand); and (3) Disruptive business models and customer access - this allows customers to influence the production to suit their needs. Examples here include 'on-site production' and 'customer engineering'.

Klaus Schwab, the CEO of the World Economic Forum, once stated; “... in this fourth revolution, we are facing a range of new technologies that combine the physical, digital and biological worlds. These new technologies will impact all disciplines, economies and industries, and even challenge our ideas about what it means to be human" (World Economic Forum, 2018). The potential for economic benefits from 4IR is becoming clearer as more organisations embrace the technologies underpinning it. The only concern is the resistance or/and unwillingness to adapt to these new technologies by some organisations and/or the risk that governments could fail to employ/regulate these technologies. Further, the shifting power created by 4IR may create important new security concerns, and that inequalities could grow rather than shrink if things are not managed properly (Schwab, 2016). The estimate by McKinsey is that as many as 47 per cents of jobs in the United States of America, are at risk from automation (Bughin, LaBerge, and Melbye, 2017). The 4IR is likely to benefit the rich more than the 
poor, especially as low-skill, low-wage jobs disappear in favour of automation. This is in line with the other three industrial revolutions - they began with greater inequality, followed by periods of political and institutional change. Given the pronounced inequalities in the South African HE sector, (South African Human Rights Commission, 2016) this could imply that the current political, business, and social structures are not ready or capable of absorbing all the changes the 4IR will bring (Sackey, S. and Bester, 2016) and that major changes to the very structure of our society are inevitable. In connection with such changes, it is said (Schwab, 2016): "The changes are so profound that, from the perspective of human history, there has never been a time of greater promise or potential peril. My concern, however, is that decision-makers are too often caught in traditional, linear (and non-disruptive) thinking or too absorbed by immediate concerns to think strategically about the forces of disruption and innovation shaping our future."

\subsection{Higher Education in the Fourth Industrial Revolution (HE 4.0)}

\subsubsection{Evolving Role of $\mathrm{HE}$}

"The central mission of higher education is the creation of prepared minds. The prepared minds contribute to the scientific, technological, economic and social development of a nation and world in general. The prepared minds innovate, create new businesses and more jobs as responsible citizens. As new innovations happen, Universities create new programmes and even new schools to focus on developing new mind-sets" (Srinivasa et al., 2013). The history of higher education (HE) can be traced back in the $6^{\text {th }}$ century's elite system that started at the monastic schools and then evolved into the medieval European University. A phenomenal change though came with 'massification' of higher education in the $20^{\text {th }}$ century. In the post- massification era, internationalisation (of both staff and students) and adaptation to social and technological changes are the key trends in the HE (Goodchild and Wechsler, 1997). In (Adams Becker, Cummins, Davis, and A., 2017), the big picture themes that define current and future HE is presented as (1)Advancing progressive learning approaches requires cultural transformation; (2) Real-world skills are needed to bolster employability and workplace development; (3) Collaboration is key for scaling effective solutions; (4) Despite the proliferation of technology and online learning materials, access is still unequal; (5) Processes for assessing nuanced skills at a personal level are needed; (6) Fluency in the digital realm is more than just understanding how to use technology; (7) Online, mobile, and blended learning are foregone conclusions; (8) Learning ecosystems must be agile enough to support the practices of the future; (9) Higher education is an incubator for developing more intuitive computers and (10) Lifelong learning is the lifeblood of higher education.

It is the thesis of this paper that 4IR can be intertwined in all these ten themes and help in improving, supporting, or extending teaching, learning, and creative inquiry within the HE's main roles of teaching, research and service to the community/society.

\subsubsection{Current and future trends in $\mathrm{HE}$}

Adam Becker et al. (2017) summarise the most prominent HE current and future trends under six categories: (1) Expanding access and convenience that enables ubiquitous learning and working from anywhere, anytime using anything; (2)Spurring of innovation and remaining 'North Star' that leads societies to the future; (3)Fostering authentic learning that entails richer and more hands-on, real-world experiences through project/challenge/competency-based learning pedagogies; (4) Tracking and evaluating evidence by ensuring capturing of a bevy of programmatic data. This enables not only performance monitoring but engagement, and behaviour as well; (5) Improving the teaching profession to cope with changing student type - the latter are more informed and highly (globally) connected. The teaching profession now changes from "sage on the stage" to "guide on the side"; and (6) Spreading digital fluency by ensuring that the proliferated digital devices are integrated into the learning process in meaningful ways. By embracing 4IR, university 
transformation should be able to produce transformative agents who can adapt to today's world (Barakabitze et al., 2019).

\subsubsection{Developments in Technologies within HE Institutions}

Advancements in technologies have completely redefined today's student; the quote (King and South, 2016) neatly captures this: "Today's average student is no longer the 18-year-old whose parents drive her up to "State $U$ " in a minivan stuffed with boxes. Instead, the "new normal" student may be a 24-year-old returning veteran, a 36-year-old single mother, a part-time student juggling work and college, or the first-generation college student. The faces we picture as our college hopefuls cannot be limited by race, age, income, zip code, disability, or any other factor. - Ted Mitchell, Under Secretary, U.S. Department of Education". In Becker et al. (2017), the following chart depicting the developments in technologies within $\mathrm{HE}$ institutions is presented in figure 1:

\begin{tabular}{l|l|l|l}
\hline $\begin{array}{l}\text { Time-to-Adoption } \\
\text { Horizon: One Year } \\
\text { or Less }\end{array}$ & $\begin{array}{l}\text { Time-to-Adoption } \\
\text { Horizon:Two to } \\
\text { Three Years }\end{array}$ \\
$\begin{array}{l}\text { Adaptive Learning Technologies } \\
\text { Mobile Learning }\end{array}$ & $\begin{array}{l}\text { The Internet of Things } \\
\text { Next-Generation LMS }\end{array}$ & $\begin{array}{l}\text { Time-to-Adoption } \\
\text { Horizon: Four to } \\
\text { Five Years }\end{array}$ \\
\hline
\end{tabular}

Figure 1. Developments in technologies within HE institutions

The most disruptive technologies that have the potential to transform life, business and the global economy have been described in (Bongomin, Gilibrays Ocen, Oyondi Nganyi, Musinguzi, and Omara, 2020). The top four in this list accordingly are mobile internet, automation of knowledge, internet of things (IoT) and cloud technology. It is further observed that most of the technologies in this list are direct/indirect enablers or are byproducts of the fourth industrial revolution. It is, therefore, safe to say that one of the main megatrends of today's HE is the fourth industrial revolution. Along this, many universities globally are already embracing 4IR technologies, but most universities in Africa, including South Africa, have not kept pace with this trend (Barakabitze et al., 2019).

\subsubsection{Higher education in the fourth industrial revolution}

It is an indisputable fact that the 4IR will 'revolutionise' the higher education sector (ButlerAdam, 2018) and perhaps end up with Higher Education Revolution 4.0 (HE 4.0). The phrase "higher education in the fourth industrial revolution for the HE 4.O" was coined by Xing and Marwala (2018) in their attempt to explore the impacts 4IR is likely to have on the mission/vision of universities globally. One widely published consequence of 4IR in the higher education space is an interdisciplinary teaching, research and innovation (Boehm, 1988; Schwab, 2016). The role of higher education in any society cannot be overemphasised; the sector's role in emerging technologies is even more critical. Given that 4IR is not a fad (Bongomin et al., 2020; Deloitte, 2018) but a reality to contend with, the future of higher education cannot be conceptualised without putting 4IR into perspective - wearing the 4IR lenses so to speak. Below in figure 2 is a summary of some of the ways that 4 IR will influence the three main functions of universities: 


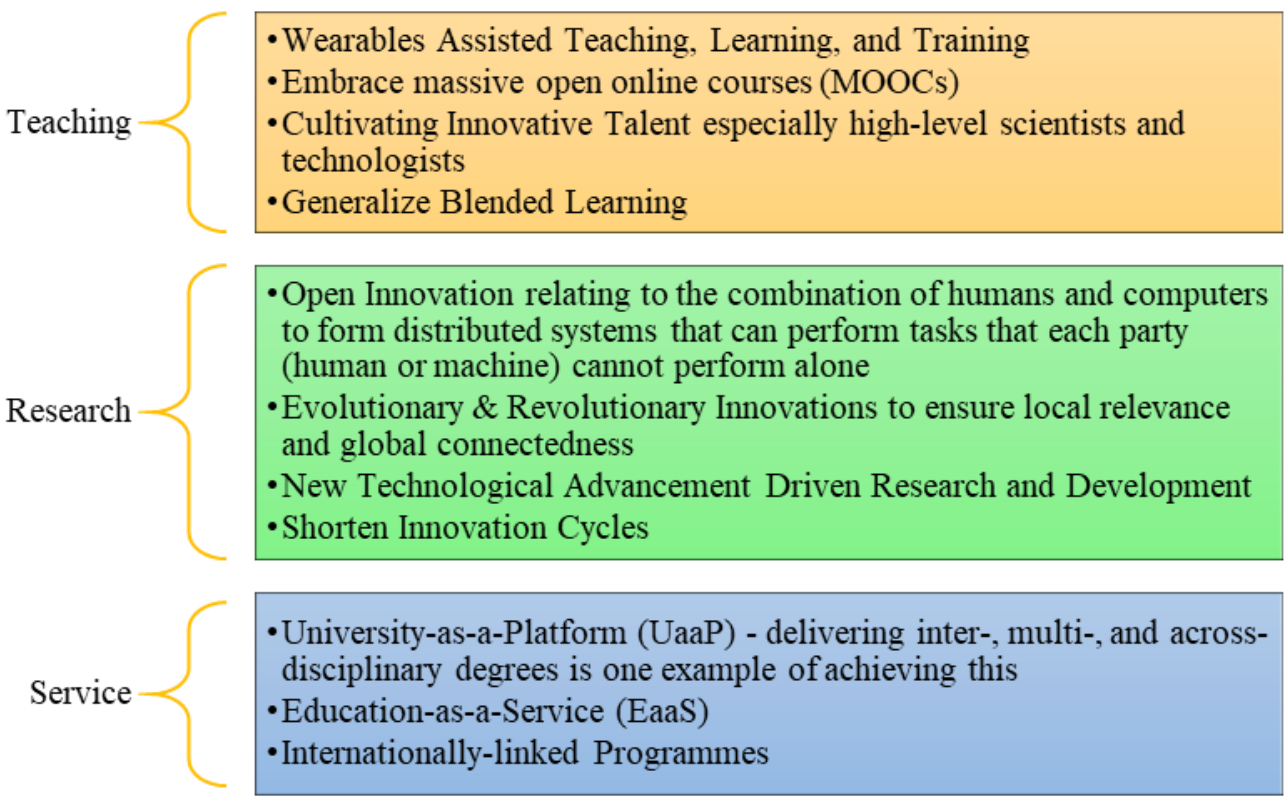

Figure 2. 4IR in HE (Xing and Marwala, 2018)

\subsubsection{Massive Open Online Courses (MOOCs)}

Among the three traditional roles of universities; namely: doing research, teaching, learning and publishing in a scholarly manner (Kulakli and Mahony, 2014), teaching and learning aspects have the greatest potential of benefiting from 4IR. This is also the space in which the transformation agenda is likely to have maximum impact. Most of this impact is as a result of the application of 4IR technologies in the management of Massive Open Online Courses (MOOCs), examples here include artificial intelligence (Jansen, van Leeuwen, Janssen, Conijn, and Kester, 2020), Web 2.0 (Social Web) technologies (Kulakli and Mahony, 2014) and gamification (Aparicio, Oliveira, Bacao, and Painho, 2019). In (Jung and Lee, 2018), MOOCs is described as unrestricted online learning environments in which the students can take courses from a variety of subjects. One of the main roles of MOOCs' is the expansion of higher education opportunities - this is in line with the transformation agenda discussed in this paper. Even though MOOCs has been widely adopted, many challenges continue to persist like those documented in (Al-Rahmi, Aldraiweesh, Yahaya, Bin Kamin, and Zeki, 2019; Hew and Cheung, 2014).

In the case of CUT and other UoTs in South Africa, the baseline challenge of students' readiness to adopt MOOCs should be investigated first. This is because, like most institutions in developing countries (Barakabitze et al., 2019), CUT lags behind when it comes to baseline technologies (Barakabitze et al., 2019; ITU, 2019). Similar students' readiness studies have carried out in Nigeria (Fakinlede, Yusuf, and Mejabi, 2014) and Malaysia (Zulkifli, Mohamed Maidin, Abd Halim, Ali, and Ahmad Kuthi, 2019) looked at three aspects of the readiness: functional, dispositional and situational. 


\subsection{Universities of Technology (UoTs)}

Universities in South Africa are classified under three types (Bunting and Cloete, 2010): (1) (Traditional) Universities that offer basic formative degrees such as Bachelor of Arts (BA) and Bachelor of Science (BSc), and professional undergraduate degrees such as Bachelor of Engineering (BScEng) and Bachelor of Medicine and Bachelor of Surgery (MBChB.). At postgraduate level, the traditional universities offer honours degrees, and a range of masters and doctoral degrees; (2) Universities of technology (UoTs) that were mainly established to offer vocational or career-focused undergraduate diplomas, and BTech which serves as a capping qualification for diploma graduates. The UoTs also offer a limited number of masters and doctoral programmes; and thirdly (3) Comprehensive universities that are supposed to offer programmes typical of university as well as programmes typical of universities of technology. After the recent addition of 3 new universities (Sol Plaatje University (SPU), the University of Mpumalanga (UMP), and Sefako Makgatho Health Sciences University), the Country now brags of 26 universities: 12 traditional, 6 comprehensives and 8 UoTs.

In the past two decades, many transformations of structural discourse in nature (Luvalo, 2019) have taken place within the South Africa's higher Education sector, many have resulted in significant developments in Universities of Technology (UoTs). The most phenomenal one is the Technikon Act of 1993 that gave the Technikons degree-awarding status. Other transformations were ushered in by the National Commission for Higher Education, appointed in 1995. This preceded the New Higher Education Act of 1997 that was meant to ensure single coordinated higher education system. Through the latter, the Technikons became UoTs in 2003. Central University of Technology, Free State (CUT) is one of these UoTs. Despite the shift to UoTs, these institutions are still seen as critical role players in the third mission of universities, that of "achieving economic growth and social progress"(Pinheiro, Langa, and Pausits, 2015), cited in (Mtshali and Sooryamoorthy, 2018).

\section{RESEARCH METHODOLOGY}

A mixed methodology was used; this comprised of bibliometric analysis, thematic analysis and survey method implemented in the form of a questionnaire. First, a bibliometric analysis of research publications related to the topic "transformation of higher education/universities" was carried out. This was achieved using data on such publications that are appearing in the Web of Science (WoS) database. The Advanced Search feature in WoS was run based on the search strings shown in Table 1 below. All these strings applied the following conditions: Indexes=SCI-EXPANDED, SSCI, A\&HCI, CPCI-S, CPCI-SSH, BKCI-S, BKCI-SSH, ESCI Timespan=All years

Table 1: The Web of Science search strings applied

\begin{tabular}{|l|c|}
\hline Search String & Number of records \\
\hline TS = ("transformation of higher education") & 116 \\
\hline TS = ("transformation of universities") & 46 \\
\hline TS = ("transforming higher education") & 58 \\
\hline TS = ("transforming university") & 21 \\
\hline TS = ("transforming universities") & 18 \\
\hline TS = ("university transformation") & 45 \\
\hline TS = ("higher education transformation") & 57 \\
\hline TS = ("university transformation") & 45 \\
\hline TS = ("universities transformation") & 20 \\
\hline TS = ("higher education sector transformation") & 1 \\
\hline
\end{tabular}

After refining the search to only include those related to the South African context, thematic analysis was carried out based on the content of the resulting scientific research articles. In 
doing so, the six phases of thematic analysis, as described in (Braun, 2006), were applied and implemented in ATLAS.ti software. The findings from this informed the survey methodology. This survey entailed the use of a questionnaire to collect data on the readiness of university students to adopt MOOCs. Similar students' readiness studies carried out in Nigeria (Fakinlede et al., 2014) and Malaysia (Zulkifli et al., 2019) looked at three aspects of the readiness: functional, dispositional and situational. Using a similar approach, a survey involving all students enrolled for various qualifications offered in the CUT's Faculty of Engineering Built Environment and IT was conducted using an online questionnaire (on Survey Monkey) between March and April 2020. This also coincided with the mandatory nation-wide lockdown instituted to curb the spread of COVID-19. To assess the students' readiness for MOOCs, this survey aimed at answering the following research questions:

i. How efficient and effective was the internet connection currently available to CUT students?

ii. Do CUT students possess an adequate functional (for MOOCs) ICT skillset?

iii. What is the CUT's students' aptitude for independent learning?

\subsection{Dataset}

A total of 3,264 students responded to the survey; their distribution per department: $11 \%$ from Built Environment, 16\% from Civil Engineering, 22\% Electrical Engineering, $31 \%$ from IT, $4 \%$ from Mathematical and Physical Sciences and 16\% from Mechanical Engineering. These equitably represented the overall student population in each of these departments. Of these students, $38 \%, 26 \%, 24 \%$ and $11 \%$ were in their $1^{\text {st }}, 2^{\text {nd }}, 3^{\text {rd }}$ and $4^{\text {th }}$ respectively. The remaining $1 \%$ were postgraduate students. While at least $85 \%$ and $10 \%$ of the students owned and access to a smartphone, respectively, the same could not be said of computer ownership and access. For the bibliometric analysis, a total of 360 publications resulted from combining the search strings in Table 1 above using OR Boolean function. In extracting the publications, the "full record and cited references" on WoS were selected.

\subsection{Data Analysis and Findings}

\subsubsection{Bibliometric Analysis}

The analysis presented in figure 3 and figure 4 below reveal a steady growth in publications under the topic "university transformation'. The results also show that indeed, South African researchers and organisations, were at the helm of investigating this topic.

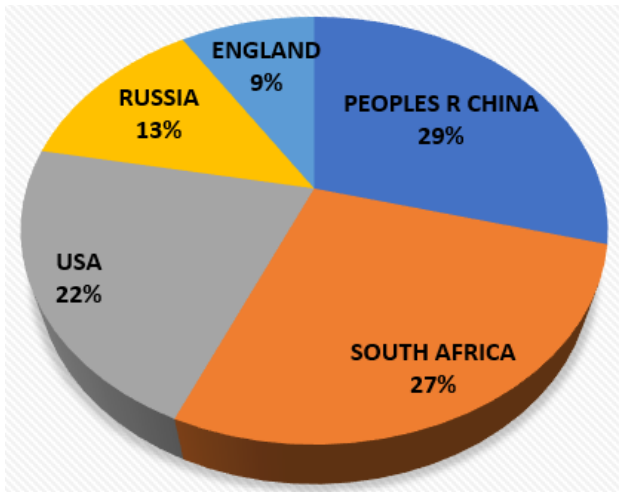

Figure 1. Distribution of publications on university transformation by country 


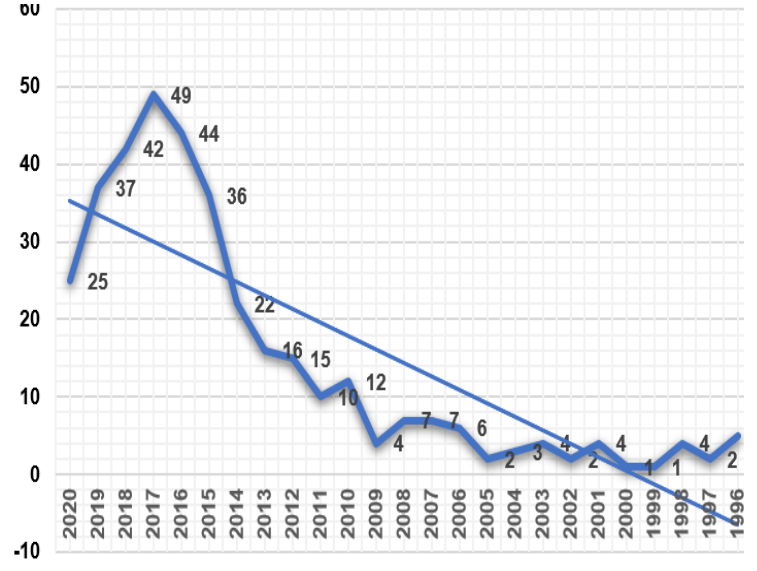

Globally

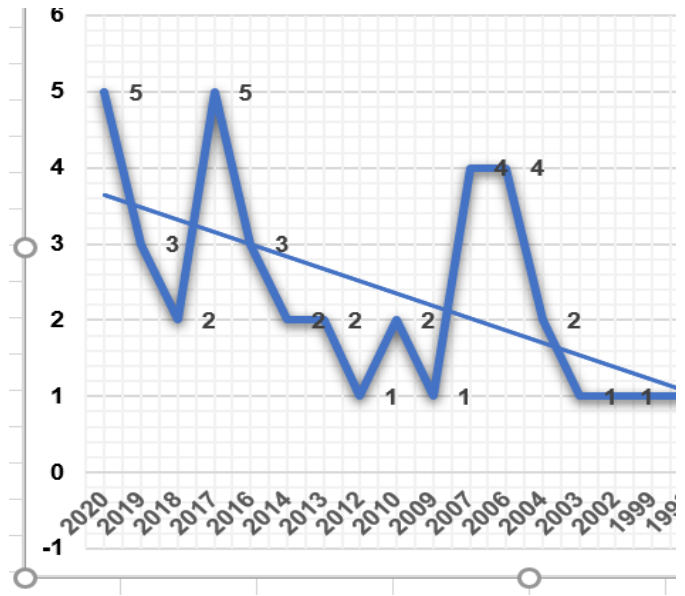

South Africa

Figure 2. Growth in the number of publications on university transformation

Using VOSview software (https://www.vosviewer.com/), further analysis of the bibliographic data of the publications was carried out. In doing so, the parameter "total link strength" was used to establish the connectedness of the main terms under university transformation research. In total, 246 items were identified with 6 clusters (each containing $64,58,56,49,15$ and 4 respectively) shown in figure 5.

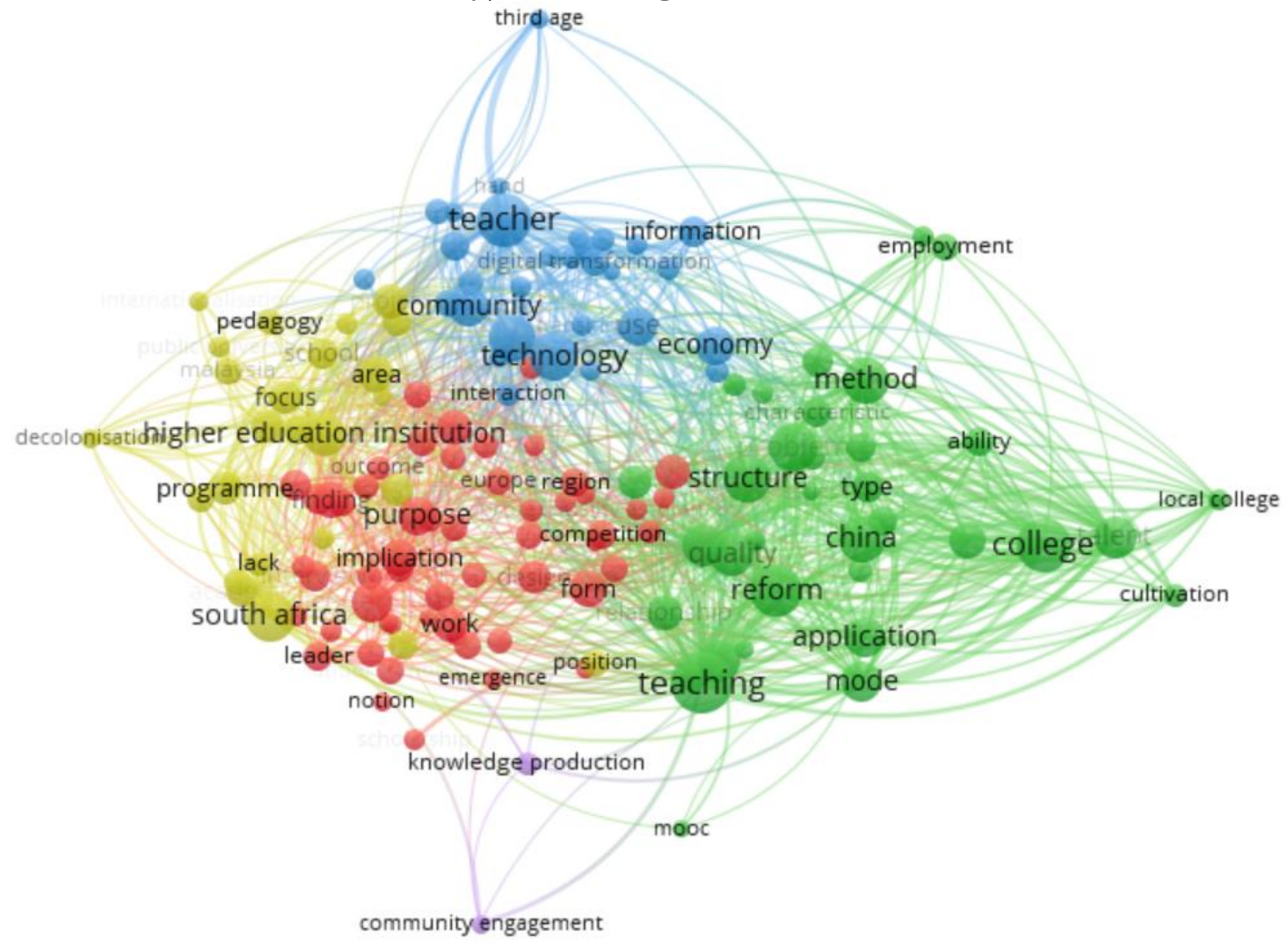

Figure 3. Network of total link strength among keywords of university transformation 
In order to focus on publications relating to South Africa only, the Search String was further reduced by combining it with the phrase "South Africa" using AND Boolean operation. This resulted in 41 publications whose network of total link strength is shown figure 6 below

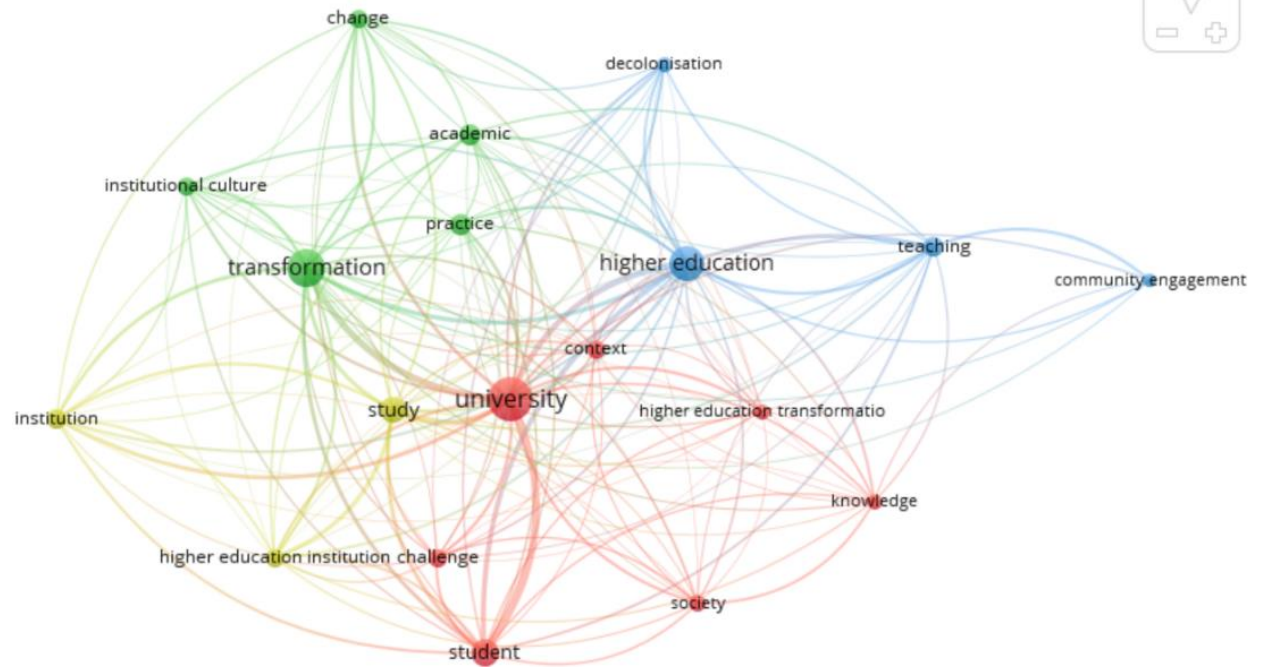

Figure 4. Network of total link strength among keywords of 'university transformation' in South Africa

Considering only those terms with a minimum of 10 occurrences in the documents, it emerges that the ten most relevant terms were: teaching, knowledge, student, university, society, higher education institution, study, decolonisation, transformation, and institutional culture, respectively. Further analysis and classification of the key phrases revealed the patterns and classifications shown in Table 2. From this, as well as figure 7 and figure 8 below, for papers related to the South African context, terms relating to technology are prominently missing while all those related to decolonisation refer to the South African context. It is also worth noting that community engagement has the highest relevance value of 4.59 under South African context. The charts in figure 7 and figure 8 further elaborate this and, also present the research areas under which most of the papers are classified as per the WoS classification. Overall, publications that focus on technology-related fields account for over $12 \%$ but only $5 \%$ for the South African context. From this, it shows that, although computer science (and its related fields) is being pursued university transformation, this was not the case in South Africa. Furthermore, the results imply that research into university transformation is mostly looked at from education research as reflected by the $54 \%$ and $65 \%$ for overall and South African context, respectively. It also reveals the lack of focus on 4IR as an agent of university transformation.

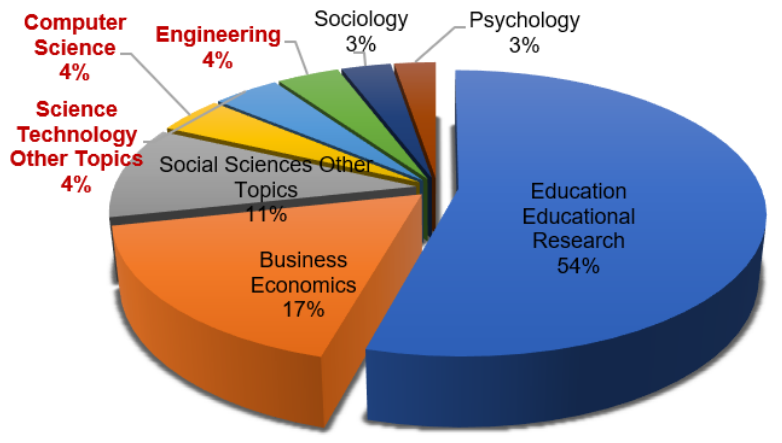

Figure 5. Distribution of publications by top research areas 


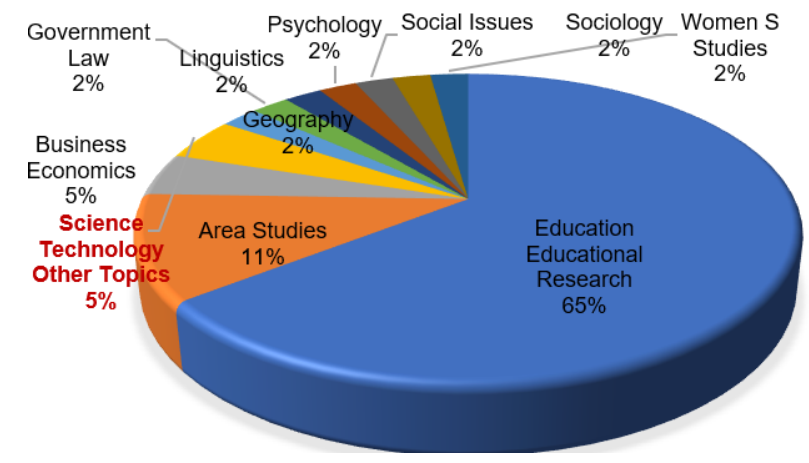

Figure 6. Distribution of publications by top research areas - South African context

Table 2: Relevance and occurrence of selected keywords of university transformation

\begin{tabular}{|c|c|c|c|c|}
\hline Technology & \multicolumn{2}{|l|}{ Overall } & \multicolumn{2}{|c|}{ South African Context } \\
\hline Term & Occurrence & Relevance & Occurrence & Relevance \\
\hline Digital Technology & 11 & 1,34 & & \\
\hline Digital transformation & 24 & 1,04 & & \\
\hline Technology & 75 & 0,51 & & \\
\hline University Roles & \multicolumn{2}{|l|}{ Overall } & \multicolumn{2}{|c|}{ South African Context } \\
\hline Term & Occurrence & Relevance & Occurrence & Relevance \\
\hline Academic Staff & 21 & 2,14 & & \\
\hline Community Engagement & 12 & 1,85 & 10 & 4,59 \\
\hline College Student & 89 & 1,62 & & \\
\hline Academic & 34 & 1,08 & & \\
\hline Teaching & 113 & 0,66 & 20 & 2,39 \\
\hline Community & 48 & 0,63 & & \\
\hline Graduate & 29 & 0,59 & & \\
\hline Society & & & 15 & 0,59 \\
\hline Teacher & 89 & 0,57 & & \\
\hline Curriculum & 25 & 0,54 & & \\
\hline Student & & & 39 & 0,83 \\
\hline University Structure & \multicolumn{2}{|l|}{ Overall } & \multicolumn{2}{|c|}{ South African Context } \\
\hline Institutional Culture & 23 & 2,38 & 17 & 0,42 \\
\hline Leader & 26 & 2,02 & & \\
\hline Institutional transformation & 14 & 1,64 & & \\
\hline Leadership & 48 & 1,38 & & \\
\hline Culture & 29 & 1,2 & & \\
\hline Governance & 24 & 0,78 & & \\
\hline Universities Transformation & 13 & 0,72 & & \\
\hline Transformation & & & 86 & 0,53 \\
\hline Reform & 84 & 0,57 & & \\
\hline University Transformation & 34 & 0,33 & & \\
\hline Others & \multicolumn{2}{|l|}{ Overall } & \multicolumn{2}{|c|}{ South African Context } \\
\hline Term & Occurrence & Relevance & Occurrence & Relevance \\
\hline Internationalisation & 11 & 4,15 & & \\
\hline Decolonisation & 11 & 1,67 & 11 & 0,6 \\
\hline Quality Assurance & 15 & 1,54 & & \\
\hline Bologna Process & 14 & 1,48 & & \\
\hline Sustainability & 20 & 1,08 & & \\
\hline
\end{tabular}




\subsubsection{Thematic Analysis}

To further analyse the terms presented under Table 2 , the data were subjected to thematic analysis. To this end, thematic analysis (using Atlas.ti software) was applied to the publications relating to South African context. Out of these, 33 publications were selected based on the availability of the manuscripts from the online databases. Given that the focus of this paper was on the application of 4IR for university transformation, the terms related to technology were expanded to include terms such as computer science, computers, ICTs, ICT, digital technology, industry revolution 4.0. All these were coded under one Code Group, as shown in figure 9. Other terms were treated in the same fashion. Further thematic analysis was carried out using code-document table with the above codes and the 33 documents. This was preceded by Word Cloud and Word List functions used to identify other most frequently occurring phrases that relate to university transformation.

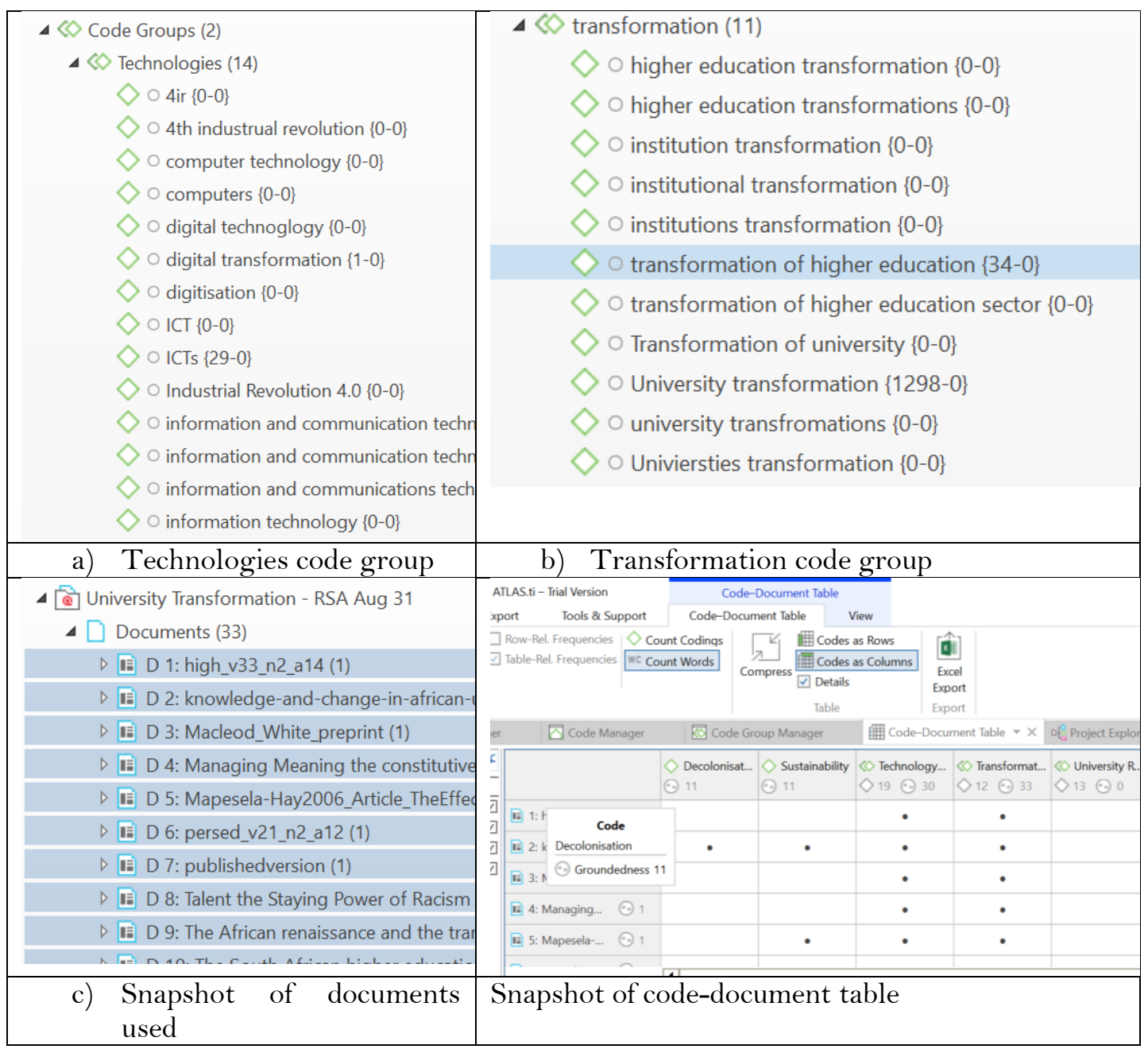

Figure 7. Illustration of thematic analysis of university transformation documents

\subsubsection{Survey data Analysis}

a) Access to Internet

For purpose of determining the issues of accessibility to internet and ICT infrastructure, the survey sought to analyse the students' current residential addresses. This was based on the confirmed patterns of ICT infrastructural development tending to be clustered around urban 
centres (ISOCARP, 2018). The results showed in Figure 9 below indicate that over $60 \%$ of students residing in the city environment owned computers while only $45 \%$ from townships owned one. More students from the IT department-owned computers compared to other departments - this is attributed to the view that a computer is a necessary learning tool for the IT students. The results also indicate that computer ownership increases as students' progress from one level of study - there are more $3^{\text {rd }}$ years $(57 \%)$ with computers compared to first years $(46 \%)$ for instance.

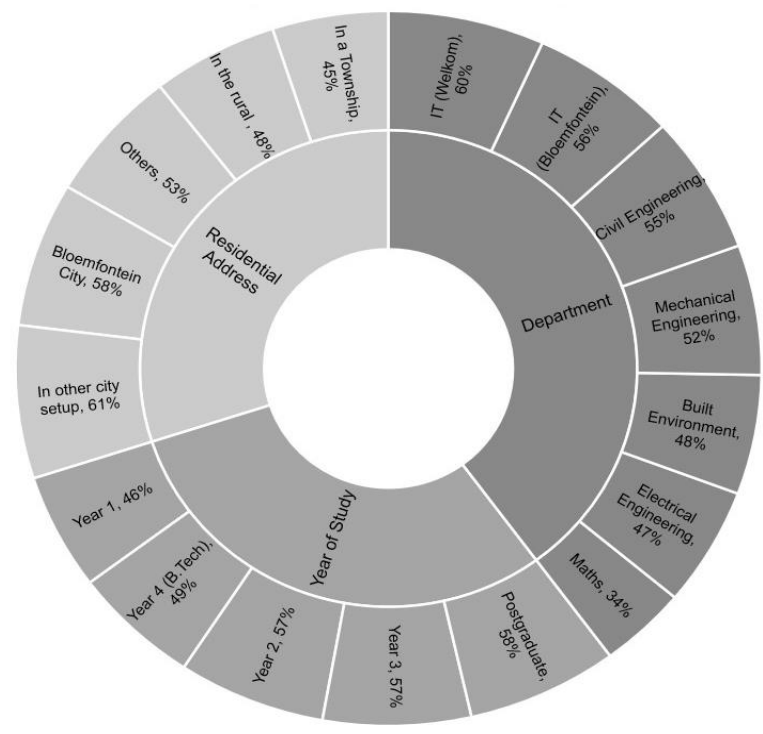

Figure 8. Computer ownership statistics by department and year of study

Further, the results in Table 3 below reflect the inequality trends in South Africa (StatsSA, 2019). For instance, while African students' computer and smartphone ownership were at $50 \%$ and $85 \%$ respectively, one of the white students stood much higher (94\% and $96 \%)$. This is also the case for a critical indicator of 'no internet access' which constitutes $14 \%$ of African and only $4 \%$ of white students. Moreover, for more 4IR supportive internet connection speeds such as ADSL/DSL and Fibre Broadband, only an insignificant number of African students have access to this. It further emerged that up to $72 \%$ of the students were/are using their phones as the main point of internet access; the representation for Mobile Broadband, Fibre Broadband and ADSL/DSL were 5\%, $3 \%$ and $2 \%$ respectively. Of concern is $14 \%$ of student who indicated that they did not have any form of internet connection.

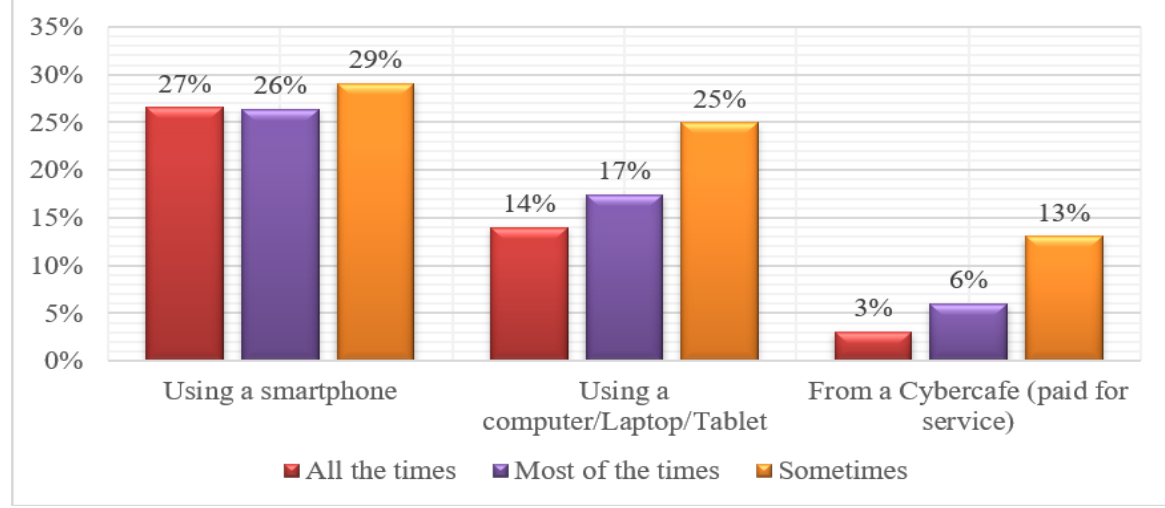

Figure 9. CUT students Internet access points 
Regarding the question on the connection used for downloading learning materials, $82 \%$ indicated that they used their phones while $56 \%$ used their computers/tablets/laptops for this. A significant $22 \%$ of student indicated that they used a Cybercafe (paid for service). These figures (see figure 11) are made of those who chose 'all the time', 'most of the time' and 'sometimes'.

Table 3: Access to ICT infrastructure by race

\begin{tabular}{|l|l|c|c|c|}
\hline & & African & Coloured & White \\
\hline Residential Address & Township & $29,2 \%$ & $9,5 \%$ & $1,6 \%$ \\
\cline { 2 - 5 } & Another city & $9,2 \%$ & $28,6 \%$ & $21,9 \%$ \\
\cline { 2 - 5 } & Rural areas & $15,2 \%$ & $7,9 \%$ & $18,0 \%$ \\
\cline { 2 - 5 } & Others & $23,5 \%$ & $17,5 \%$ & $14,8 \%$ \\
\cline { 2 - 5 } & Bloemfontein City & $22,9 \%$ & $36,5 \%$ & $43,8 \%$ \\
\hline A quiet place to study from while at home & Yes & $56,3 \%$ & $65,1 \%$ & $88,3 \%$ \\
\hline Smartphone ownership & No & $5,2 \%$ & $4,8 \%$ & $0,0 \%$ \\
\cline { 2 - 5 } & No (I have access) & $10,2 \%$ & $0,0 \%$ & $3,9 \%$ \\
\cline { 2 - 5 } & Yes & $84,5 \%$ & $95,2 \%$ & $96,1 \%$ \\
\hline Computer or laptop ownership & No & $40,1 \%$ & $25,4 \%$ & $7,0 \%$ \\
\cline { 2 - 5 } & No (I have access) & $10,0 \%$ & $7,9 \%$ & $1,6 \%$ \\
\cline { 2 - 5 } & Yes & $49,9 \%$ & $66,7 \%$ & $91,4 \%$ \\
\hline Type of primary internet access & ADSL/DSL & $0,9 \%$ & $17,5 \%$ & $21,9 \%$ \\
\cline { 2 - 5 } & Fibre Broadband & $1,6 \%$ & $4,8 \%$ & $31,3 \%$ \\
\cline { 2 - 5 } & From my smart phone & $74,0 \%$ & $49,2 \%$ & $26,6 \%$ \\
\cline { 2 - 5 } & Mobile Broadband & $5,1 \%$ & $9,5 \%$ & $11,7 \%$ \\
\cline { 2 - 5 } & NONE & $14,2 \%$ & $9,5 \%$ & $3,9 \%$ \\
\cline { 2 - 5 } & Other (please specify) & $4,1 \%$ & $9,5 \%$ & $4,7 \%$ \\
\hline
\end{tabular}

The commitment and assessment of online learning resources were assessed through three questions whose results are shown in Table 4 below. The issue of accessibility to the CUT online library was rated lower than $50 \%$.

Table 4: Commitment and Assessment of online learning resources

\begin{tabular}{|l|c|}
\hline Dimension & $\begin{array}{c}\text { Weighted } \\
\text { Average }\end{array}$ \\
\hline Access to eThuto is satisfactory & 2.15 \\
\hline $\begin{array}{l}\text { Access to CUT online library (e.g., electronic databases and books) is } \\
\text { satisfactory }\end{array}$ & 1.5 \\
\hline Online learning should be adopted to mitigate the effects by COVID 19 & 2.39 \\
\hline
\end{tabular}

For internet affordability assessment, the monthly prices that the students pay to access the internet were gauged using the parameters shown in Figure 12. Most of the students' expenses range from less than 100 Rand to 300 Rand. This is considered affordable since it does not go over $1 \mathrm{R}$ per day. Students were responding to the question: "How much can you afford to pay for accessing internet PER MONTH?" 


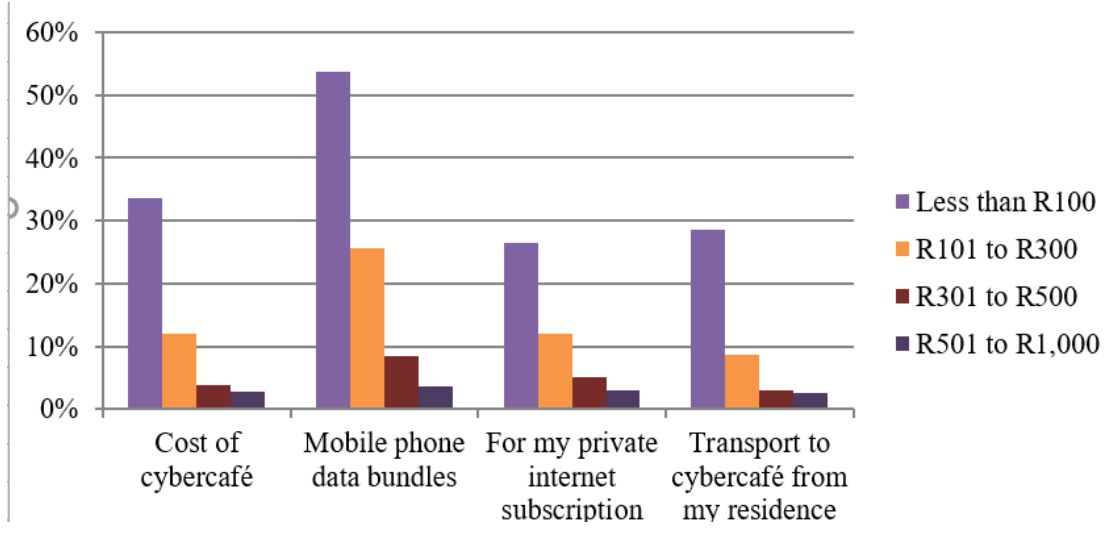

Figure 10. Cost of internet for CUT students

b) Functional ICT Skills

Three basic ICT Skills were assessed through a 4-scale measure made up of 'No Skill -1', 'Beginner level $=2$ ', 'Intermediate $=3$ ' and 'Expert $=4$ '. The results in Figure 13 below indicate that the students possess above 'intermediate' (except for 'reference and citations' skill) functional ICT Skills.

c) Independent Learning Skills

A total of 11 aspects of independent learning skills were assessed using a 5-Lickert scale made up Strong Agree, Agree, Neutral, Disagree and Strongly Disagree. Out of a possible score of 4, the results shown in Table 5 indicates high (more than $60 \%$ ) students' aptitude' for three of the independent learning skills.

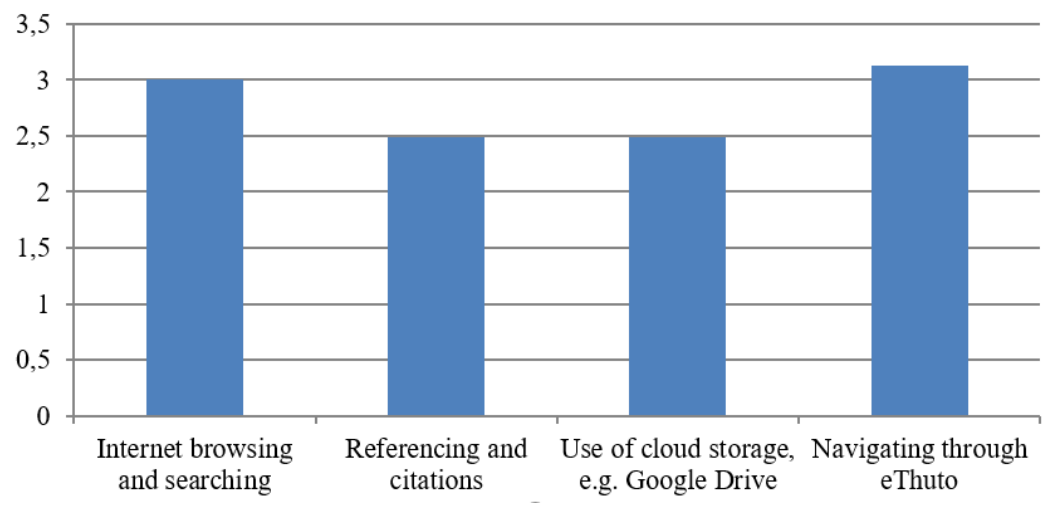

Figure 11. Level of Functional ICT Skills among CUT students

Table 5: Level of independent learning skills among CUT Students

\begin{tabular}{|l|c|}
\hline Dimension & $\begin{array}{c}\text { Weighted } \\
\text { Average }\end{array}$ \\
\hline I do not quit just because things get difficult & 2,75 \\
\hline I have to read something to learn it best & 2,73 \\
\hline I can learn from things I hear like lectures, audio recordings or podcasts & 2,71 \\
\hline I like to learn in a group, but I can learn on my own as well & 2,5 \\
\hline I finish the online projects I start & 2,25 \\
\hline I am good at setting goals and deadlines for myself & 2,18 \\
\hline I can learn from various instructional formats & 2,04 \\
\hline I remain motivated even though the instructor is not online at all times & 1,99 \\
\hline
\end{tabular}




\begin{tabular}{|l|c|}
\hline I have a really good reason for taking an online course & 1,97 \\
\hline I can complete my online works/assignments even when there are distractions & 1,97 \\
\hline I learn things online easily & 1,61 \\
\hline
\end{tabular}

\section{DISCUSSION, CONCLUSION AND RECOMMENDATION}

The research reported in this paper aimed at conceptualising a roadmap for adopting technologies associated with the Fourth Industrial Revolution (4IR) as the agent for implementing university transformation. With the focus on the unique opportunities and challenges facing South Africa's Universities of Technology (UoTs), this was preceded by the analysis of scientific publications focusing on the topic 'university transformation'. A survey on the readiness of UoTs' students to adopt 4IR technologies for learning was also carried out. The results discussed above confirm among other things: (1) existence of inequality among students (2) emphasis on decolonisation and community engagement as main themes by South African researcher who have published on the topic university transformation; (3) Very insignificant focus on 4IR as a theme for university transformation. Based on these findings, the roadmap below is proposed.

\subsection{University Transformation Roadmap for CUT - Role of 4IR}

CUT and indeed, other universities in South Africa, have taken up the recommendations in the South African Human Rights Commission report on transforming public universities (South African Human Rights Commission, 2016) and instituted a university-level transformation agenda. The CUT 2016-2020 Transformation Plan (CUT, 2016) contains the implementation plan for this transformation agenda. The following 11 projects are prioritised in this Plan:(1) Student and staff equity and redress; (2) Diversity and inclusivity, discrimination and racism;(3) Institutional culture and climate: - Institutional governance and management; (4) Language policy matters; (5) Curriculum transformation; (6) Programme and Qualification Mix (PQM); (7) Teaching and learning; (8) Student learning support; (9) Staff development and support; (10) Research and development; and (11) Community engagement.

Based on the literature reviewed and presented in the preceding sections of this paper, a blueprint on how CUT's top management can leverage 4IR to ensure implementation and success of 6 of the 11 priority projects contained in the CUT's transformation plan is presented in Table 6 below.

Table 6. CUT Transformation plan's implementation through 4IR (Source: Author)

\begin{tabular}{|c|c|}
\hline $\begin{array}{l}\text { Transformation } \\
\text { Project }\end{array}$ & Fourth Industrial Revolution Leverage \\
\hline $\begin{array}{l}\text { Teaching and } \\
\text { learning }\end{array}$ & $\begin{array}{l}\text { - Adoption of wearables in teaching, learning and assessment-CUT can, for } \\
\text { example, take advantage of the proliferation of cyber-physical systems in }\end{array}$ \\
\hline $\begin{array}{l}\text { Student } \\
\text { learning } \\
\text { support }\end{array}$ & $\begin{array}{l}\text { teaching and learning of topics such as numerical simulations under STEM } \\
\text { subjects. Advancements in the field of augmented reality can also be used to } \\
\text { bridge education accessibility gaps. This is by way of superimposing } \\
\text { computer-generated information. } \\
\text { - Adoption of Massive Open Online Courses (MOOCs) through an off-campus } \\
\text { and online model of teaching and learning. This not only expands access and } \\
\text { convenience, but it also ensures that CUT is able to overcome the access (to } \\
\text { education) limitations resulting from limited resources (lecture rooms and } \\
\text { human resources). Further, being contactless, the real and imagined } \\
\text { discrimination of students and staff will be minimised. } \\
\text { - Inculcating the culture of innovation among the students and staff members } \\
\text { through the interdisciplinary environments that characterise 4IR. Further, }\end{array}$ \\
\hline
\end{tabular}




\begin{tabular}{|c|c|}
\hline & $\begin{array}{l}\text { 4IR creates an innovation climate that enables understanding of humanities } \\
\text { and social science and vice versa. } \\
\text { - CUT should adopt generalised blended learning that entails mixed e-learning } \\
\text { and face-to-face methodology. The power of 4IR will make this even more } \\
\text { feasible and its adoption will make it easier for students to develop } \\
\text { expressions and problem-solving capabilities. Consequently, the current } \\
\text { failure rates, especially of STEM courses will be reduced significantly. } \\
\text { - Use 4IR technologies to implement lifelong learning that is able to prioritise } \\
\text { and recognise ongoing learning for all students; in both formal and informal } \\
\text { settings } \\
\text { - Use 4IR technologies to redesign learning spaces that are able to support } \\
\text { organic interactions and cross-disciplinary problem-solving. }\end{array}$ \\
\hline $\begin{array}{l}\text { Staff } \\
\text { development } \\
\text { and support }\end{array}$ & $\begin{array}{l}\text { - Use 4IR technologies to implement lifelong learning that is able to prioritise } \\
\text { and recognise ongoing learning for all staff members - in both formal and } \\
\text { informal settings } \\
\text { - Innovative training programmes aimed at transforming the teaching } \\
\text { profession. This is because lecturers of tomorrow need to understand the shift } \\
\text { from their position as "sage on the stage" to "guide on the side." }\end{array}$ \\
\hline $\begin{array}{l}\text { Research and } \\
\text { development }\end{array}$ & $\begin{array}{l}\text { - Spawn multidisciplinary open innovation projects that involve machine- } \\
\text { human federations. Such include crowdsourcing for workflows and micro- } \\
\text { tasking by leveraging the strengths of crowds and machines. } \\
\text { - Adopt a hybrid of evolutionary and revolutionary research projects. This will } \\
\text { enable the researchers to have both 'inward' and 'outward' research outlook } \\
\text { that has both local (internally, locally and regionally) and global perspective. } \\
\text { This will reduce the current 'marginalisation' feeling among some staff } \\
\text { members and students. } \\
\text { - 4IR Technology-driven RandD - CUT is already doing this to some extent. } \\
\text { This is especially so through the Centre for Rapid Prototyping where } \\
\text { hundreds of } 3 \mathrm{D} \text { printing projects have been implemented over the years. In } \\
\text { line with this, the University also recently re-aligned the research themes to } \\
\text { technology-driven ones. More work needs to be done in ensuring the } \\
\text { involvement of the majority of staff members and students. }\end{array}$ \\
\hline \multirow[t]{2}{*}{$\begin{array}{l}\text { Curriculum } \\
\text { transformation } \\
\text { Community } \\
\text { engagement } \\
\text { Programme } \\
\text { and } \\
\text { Qualification } \\
\text { Mix (PQM) }\end{array}$} & $\begin{array}{l}\text { - Adoption of a University-as-a-Platform (UaaP) model that provides the } \\
\text { stakeholders with customised service platforms (e.g., students' learning } \\
\text { environments) through ubiquitous computing and Internet of things. In such } \\
\text { environments, students with slower internet speeds do not experience } \\
\text { 'discrimination'. This will also encourage other aspects of UaaP, such as the } \\
\text { delivery of inter-, multi-, and cross-disciplinary degrees. Such a platform will } \\
\text { also lead to the expansion of CUT's community engagement portfolio }\end{array}$ \\
\hline & $\begin{array}{l}\text { - Adoption of Education-as-a-Service (EaaS) model on the backdrop of the fact } \\
\text { that CUT is accountable to a host of stakeholders such as provincial and } \\
\text { national governments, accrediting agencies such as the Engineering Council } \\
\text { of South Africa (ECSA) and the financiers. In the realm of 4IR, it will become } \\
\text { possible to create a smooth EaaS through the discovery of newer and more } \\
\text { advanced strategies for coping with the ever-increasing societal complexity. } \\
\text { - Implementation of internationally linked programmes through various } \\
\text { national and international institutional linkages. These will enable } \\
\text { sustainable implementation of more versatile degree programmes and } \\
\text { professional qualifications required in the 4IR. Collaboratively awarding } \\
\text { degrees through models such as twining programmes, franchise programmes } \\
\text { and awarding of double or joint degree will become both a reality and a must } \\
\text { in the 4IR. }\end{array}$ \\
\hline
\end{tabular}




\subsection{Recommendations}

At the dawn of the fourth industrial revolution, institutions (public and private) need to identify transformative ways of reimagining their mission and vision. This should be approached in a way that is aligned to this revolution - otherwise not doing so will leave a lost window of opportunity. In the case of higher education institutions such as CUT, such alignments should be anchored on the three functions of the universities: teaching, research and (community) service.

CUT, like other public universities in South Africa, is currently undergoing a mandatory transformation geared towards addressing the inequalities created by the past apartheid government system. Although there are already isolated efforts towards embracing 4IR, this paper has attempted to present a blueprint that CUT could adopt in ensuring that the transformation agenda benefits from the opportunities presented by 4IR.

In this paper, a detailed blueprint of how CUT can anchor its transformation agenda within 4IR is presented. Given that the audience of this paper is the top management of the university, it is recommended that is blueprint be adopted and be used to expand the terms of reference of the recently created 4IR Task Team. Given the similarities of the transformation agenda of other UoTs, it is further recommended that other UoTs adopt and adapt this blueprint to accelerate their transformation processes.

In recognition of the critical role of MOOCs in expanding accessibility to teaching and learning, the paper also provides preliminary results on the students' readiness to this form of learning. This is underpinned by the assertion that most students at UoTs lag in terms of baseline computing infrastructure. Other aspects of the transformation agenda as explained in Table 6 also need to be pursued in order to cater for all three of the missions of the university - especially the aspects of community engagement, research and innovation.

\section{REFERENCES}

Adams Becker, S., Cummins, M., Davis, A., and A., F. (2017). NMC Horizon Report: 2017 Higher Education Edition (2017th ed.; C. A., Hall Giesinger and V. Ananthanarayanan, Eds.). Retrieved from The New Media Consortium

Al-Rahmi, W., Aldraiweesh, A., Yahaya, N., Bin Kamin, Y., and Zeki, A. M. (2019). Massive Open Online Courses (MOOCs): Data on higher education. Data in Brief, 22, 118-125. https://doi.org/10.1016/j.dib.2018.11.139

Altbach, P. G., Reisberg, L., and Rumbley, L. E. (2009). Trends in Global Higher Education : Tracking an Academic Revolution. UNESCO 2009 World Conference on Higher Education. https://doi.org/10.1016/j.bse.2004.04.006

Aparicio, M., Oliveira, T., Bacao, F., and Painho, M. (2019). Gamification: A key determinant of massive open online course (MOOC) success. Information and Management, 56(1), 39-54. https://doi.org/10.1016/j.im.2018.06.003

Barakabitze, A. A., Lazaro, A. W., Ainea, N., Mkwizu, M. H., Maziku, H., Matofali, A. X., .. Sanga, C. (2019). Transforming African Education Systems in Science, Technology, Engineering, and Mathematics ( STEM) Using ICTs : Challenges and Opportunities. Education Research Internationa, 2019, 1-29.

Barr, C. (2017). Inequality index: where are the world's most unequal countries. The Guardian.

Bloem, J., Van Doorn, M., Duivestein, S., Excoffier, D., Maas, R., and Van Ommeren, E. (2014). The Fourth Industrial Revolution Things to Tighten the Link Between it and ot. In VINT research report.

Boehm, B. W. (1988). A Spiral Model of Software Development and Enhancement. 29(8), 700-703. https://doi.org/10.1177/070674378402900812 
Bond, P. (2007). Transcending two economies: renewed debates in South African political economy. Africanus. Journal of Development Studies.

Bongomin, O., Gilibrays Ocen, G., Oyondi Nganyi, E., Musinguzi, A., and Omara, T. (2020). Exponential Disruptive Technologies and the Required Skills of Industry 4.O. Journal of Engineering, 2020. https://doi.org/10.1155/2020/4280156

Braun, V. (2006). Using thematic analysis in psychology. Qualitative Research in Psychology, 3(2), 77-101.

Bughin, J., LaBerge, L., and Melbye, A. (2017). The case for digital reinvention (McKinsey Quarterly).

Bunting, I., and Cloete, N. (2010). Institutional types in higher education in South Africa. https://doi.org/10.1080/07366981.2014.869962

CUT. (2016). CUT Transformation Plan 2016-2020. pp. 1-27. Retrieved from www.cut.ac.za

Deloitte. (2018). The fourth industrial revolution is here: Are you ready? Deloitte Insight. https://doi.org/10.1016/j.jbusres.2015.10.029

Fakinlede, C. O., Yusuf, M. O., and Mejabi, O. V. (2014). Readiness for online learning in higher education: a mixed methods assessment of students at a Nigerian University. Malaysian Journal of Distance Education, 16(1), 37-57.

Hew, K. F., and Cheung, W. S. (2014). Students' and instructors' use of massive open online courses (MOOCs): Motivations and challenges. Educational Research Review, 12, 4558. https://doi.org/10.1016/j.edurev.2014.05.001

ISOCARP. (2018). Cool planning: changing climate and our urban future: Proceedings of 54.th ISOCARP Congress (D. Bogunovich, Ed.). Retrieved from https://isocarp.org/

ITU. (2019). International Telecommunication Union, Facts and Figures. Retrieved 1 March 2020, from https://www.itu.int/en/ITU-D/Statistics/Pages/stat/default.aspx

Jansen, R. S., van Leeuwen, A., Janssen, J., Conijn, R., and Kester, L. (2020). Supporting learners' self-regulated learning in Massive Open Online Courses. Computers and Education, 146(November 2019). https://doi.org/10.1016/j.compedu.2019.103771

Jung, Y., and Lee, J. (2018). Learning Engagement and Persistence in Massive Open Online Courses (MOOCS). Computers and Education, 122(April 2017), 9-22. https://doi.org/10.1016/j.compedu.2018.02.013

Kelly, E. P. (1998). Competing in the Third Wave: The Ten Key Management Issues of the Information Age. Academy of Management Perspectives. https://doi.org/10.5465/ame.1998.254984

Kulakli, A., and Mahony, S. (2014). Knowledge Creation and Sharing with Web 2.0 Tools for Teaching and Learning Roles in So-called University 2.0. Procedia - Social and Behavioral Sciences, 150, 648-657. https://doi.org/10.1016/j.sbspro.2014.09.084

Luvalo, L. M. (2019). Relationship Between Transformation and Institutional Culture. South African Journal of Higher Education, 33(1), 184-199.

Mosconi, F. (2015). The new European industrial policy: Global competitiveness and the manufacturing renaissance. In The New European Industrial Policy: Global Competitiveness and the Manufacturing Renaissance. https://doi.org/10.4324/9781315761756

Mtshali, M. N. G., and Sooryamoorthy, R. (2018). A research-inducing environment at a University of Technology in South Africa: Challenges and future prospects. Futures, (June), o-1. https://doi.org/10.1016/j.futures.2018.06.017

Pinheiro, R., Langa, P. V., and Pausits, A. (2015). One and two equals three? The third mission of higher education institutions. European Journal of Higher Education. https://doi.org/10.1080/21568235.2015.1044552

Preez, P., Simmonds, S., and Campus, P. (2016). Rethinking and researching transformation in higher education : A meta-study of South African trends. Transformation in Higher Education, 1(1), 1-7. 
Roblek, V., Meško, M., and Krapež, A. (2016). A Complex View of Industry 4.0. SAGE Open, 6(2). https://doi.org/10.1177/2158244016653987

SACHR. (2018). Achieving substantive economic equality through rights-based radical socio-economic transformation in South Africa. Pretoria.

Sackey, S., M., and Bester, A. (2016). Industrial Engineering Curriculum in Industry 4.0 in a South African Context. The South African Journal of Industrial Engineering, 27(4), 101-114. Retrieved from http://sajie.journals.ac.za/pub/article/view/1579/746

Sackey, S. M., and Bester, A. (2016). Industrial engineering curriculum in industry 4.0 in a South African context. South African Journal of Industrial Engineering. https://doi.org/10.7166/27-4-1579

Schwab, K. (2016). The Fourth Industrial Revolution: what it means and how to respond. World Economic Forum, 1-7.

Soudien-Report. (2008). 30 November 2008 - Final Report. Pretoria.

Srinivasa, P. L., Nagananda, S. N., Kadambi, G. R., Hariharan, R., Shankpal, P., and Shankapal, S. R. (2013). Development of two degree of freedom (DoF) bionic hand for below elbow amputee. 2013 IEEE International Conference on Electronics, Computing and Communication Technologies, 1-6.

StatsSA. (2019). Inequality Trends in South Africa: A multidimensional diagnostic of inequality. Pretoria.

United Nations Development Programme. (2019). Human Development Report 2019: Beyond income , beyond averages , beyond today. Retrieved from http://hdr.undp.org/sites/default/files/hdr2019.pdf

World Economic Forum. (2018). The Future of Jobs Report. In Centre for the New Economy and Society. https://doi.org/10.1177/0891242417690604

Xing, B., and Marwala, T. (2018). Implications Of The Fourth Industrial Age On Higher Education. Tạp Chí Nghiên Cứu Dân Tộc. https://doi.org/10.25073/0866-773x/87

Zulkifli, N. Z., Mohamed Maidin, F. B., Abd Halim, A. H., Ali, U. H., and Ahmad Kuthi, H. A. (2019). Students' readiness in using MOOC for teaching and learning. Journal of Counseling and Educational Technology, 2(2). https://doi.org/10.32698/0281 